\title{
PRODUÇÃO DE AÇOS DAS CLASSES DE RESISTÊNCIA DE 80 E 90 KSI VIA TMCP NO LAMINADOR DE CHAPAS GROSSAS DA GERDAU OURO BRANCO *
}

\author{
Romeu Thomaz Viana $\mathrm{Jr}^{1}$ \\ Adenilson Rosário Vitor ${ }^{2}$ \\ Antônio Augusto Gorni \\ José Herbert Dolabela da Silveira ${ }^{4}$ \\ Juliana de Fatima Maia ${ }^{5}$ \\ Rafael Abreu Fraga ${ }^{6}$ \\ Ricardo José de Faria
}

\section{Resumo}

Este trabalho tem como objetivo apresentar a implantação de tratamentos termomecânicos no novo laminador de chapas grossas da Gerdau Ouro Branco, descrevendo seus mecanismos metalúrgicos e o correspondente efeito nos produtos. Para melhor ilustrar essa atividade, tomou-se como exemplo os resultados de testes bem sucedidos de aços estruturais de alta resistência e baixa liga, graus 80 e $90 \mathrm{ksi}$ (550 e $620 \mathrm{MPa}$, respectivamente), com microestrutura predominantemente bainítica.

Palavras-chave: Chapas grossas graus 80 e 90 ksi; Tratamento termomecânico; Propriedades mecânicas; Microestrutura.

\section{PRODUCTION OF STEELS OF 90 KSI RESISTANCE CLASS USING TMCP IN THE PLATE MILL OF GERDAU OURO BRANCO}

\section{Abstract}

This paper aims to present the implantation of thermomechanical treatments in the new plate mill of Gerdau Ouro Branco, describing its metallurgical mechanisms and the corresponding effect on the products. To illustrate this approach, the results of successful tests of a 80 and $90 \mathrm{ksi}$ (550 and $620 \mathrm{MPa}$, respectively) high strength, low alloy structural steel with predominantly bainitic microstructure were taken as an example.

Keywords: 80 and 90 ksi heavy steel plates; Thermomechanical treatment; Mechanical properties; Microstructure.

1 Engenheiro Metalurgista, Assessor Técnico, Gerência de P\&D, Gerdau, Ouro Branco, MG, Brasil.

2 Técnico em Metalurgia, Laboratorista, Gerência de Laboratórios, Gerdau, Ouro Branco, MG, Brasil.

3 Engenheiro de Materiais, M. Eng., Dr. Eng., Consultor Técnico, Gerência de P\&D, Gerdau, Ouro Branco, MG, Brasil.

4 Engenheiro Metalurgista, M. Eng., Gerente de Chapas Grossas, Gerência de Chapas Grossas, Gerdau, Ouro Branco, MG, Brasil.

5 Técnico em Metalurgia, Laboratorista, Gerência de Laboratórios, Gerdau, Ouro Branco, MG, Brasil.

6 Engenheiro Metalurgista, Assessor Técnico, Gerência de Chapas Grossas, Gerdau, Ouro Branco, MG, Brasil.

7 Engenheiro Metalurgista, M. Eng., Assessor Técnico, Gerência de P\&D, Gerdau, Ouro Branco, MG, Brasil. 


\section{INTRODUÇÃO}

Há cinquenta anos, a laminação a quente era conduzida quase que exclusivamente para modificar as dimensões dos produtos. Seus parâmetros eram definidos buscando maximizar a produtividade da linha sem exceder seus limites, e com amplas faixas de amplitude para facilitar a operação. Nos casos mais críticos, onde a laminação a quente não conseguia proporcionar as propriedades mecânicas desejadas ao produto, procedia-se então ao seu tratamento térmico, em condições bem mais controladas de evolução de temperatura. Essa situação até era compreensível naquela época, considerando-se as limitações industriais então existentes em termos de equipamentos, automação, instrumentação e conhecimento sobre a metalurgia do aço.

Mas ficava a questão: afinal, por que não obter o produto acabado diretamente da laminação a quente, eliminando-se um novo reaquecimento? A princípio, desde que haja compatibilidade entre as evoluções de temperatura da laminação a quente e do tratamento térmico, pode-se pensar em unir esses dois processos num só, dando origem ao chamado tratamento termomecânico. Ele abrevia a cadeia de processos, mas requer cuidado e disciplina durante sua execução, requerendo coordenação precisa entre os momentos em que as deformações são aplicadas ao esboço de laminação e sua evolução de temperatura para que ocorram as transformações metalúrgicas necessárias para se obter propriedades finais desejadas pelo cliente. $O$ risco de erro durante a execução manual desse procedimento é relativamente alto; além disso, imprecisões na medição da temperatura - causadas, por exemplo, pela presença de água, vapor ou carepa grosseira sobre o esboço - também podem comprometer os resultados obtidos.

O atual ambiente econômico favorece amplamente a racionalização proporcionada pelos tratamentos termomecânicos. O mercado siderúrgico tornou-se muito mais competitivo, exigindo que as usinas se tornassem mais eficientes e reduzissem 0 custo de seus produtos. Os ciclos de resfriamento e aquecimento do produto que está sendo processado foram questionados e eliminados ao máximo. O progresso da ciência metalúrgica, juntamente 0 ocorrido nas áreas da informática, instrumentação e mecânica, permitiu melhor controle dos parâmetros de processo da laminação a quente, viabilizando a aplicação consistente dos tratamentos termomecânicos. Assim se tornou possível dispensar o tratamento térmico adicional em vários tipos de produtos - o qual incorre em maiores custos, impactos ecológicos e prazos de entrega [1].

Por outro lado, os tratamentos termomecânicos de produtos planos somente se tornaram uma rota de produção bastante efetiva quando ocorreu uma revolução na metalurgia ferrosa através do desenvolvimento dos chamados aços de alta resistência e baixa liga (ARBL), contendo micro-adições de $\mathrm{Nb}, \mathrm{Ti}$ e/ou $\mathrm{V}$. O objetivo aqui é intensificar o refino do tamanho de grão da microestrutura, conseguindo dessa forma altos níveis tanto de resistência mecânica como de tenacidade - por sinal, esse é o único mecanismo de endurecimento que promove aumento simultâneo nessas duas propriedades antagônicas. Isso é conseguido através da adoção de ligas apresentando composições químicas especialmente desenvolvidas, as quais são laminadas a quente obedecendo a uma sincronia bem específica entre as deformações aplicadas e as temperaturas em que elas ocorrem. 
A figura 1 [2] mostra os mecanismos metalúrgicos envolvidos na laminação controlada dos aços microligados, um dos tratamentos termomecânicos mais comuns, onde se pode observar a ação do $\mathrm{Nb}$ ao longo do processo, o qual possui papel fundamental na definição das microestruturas obtidas.

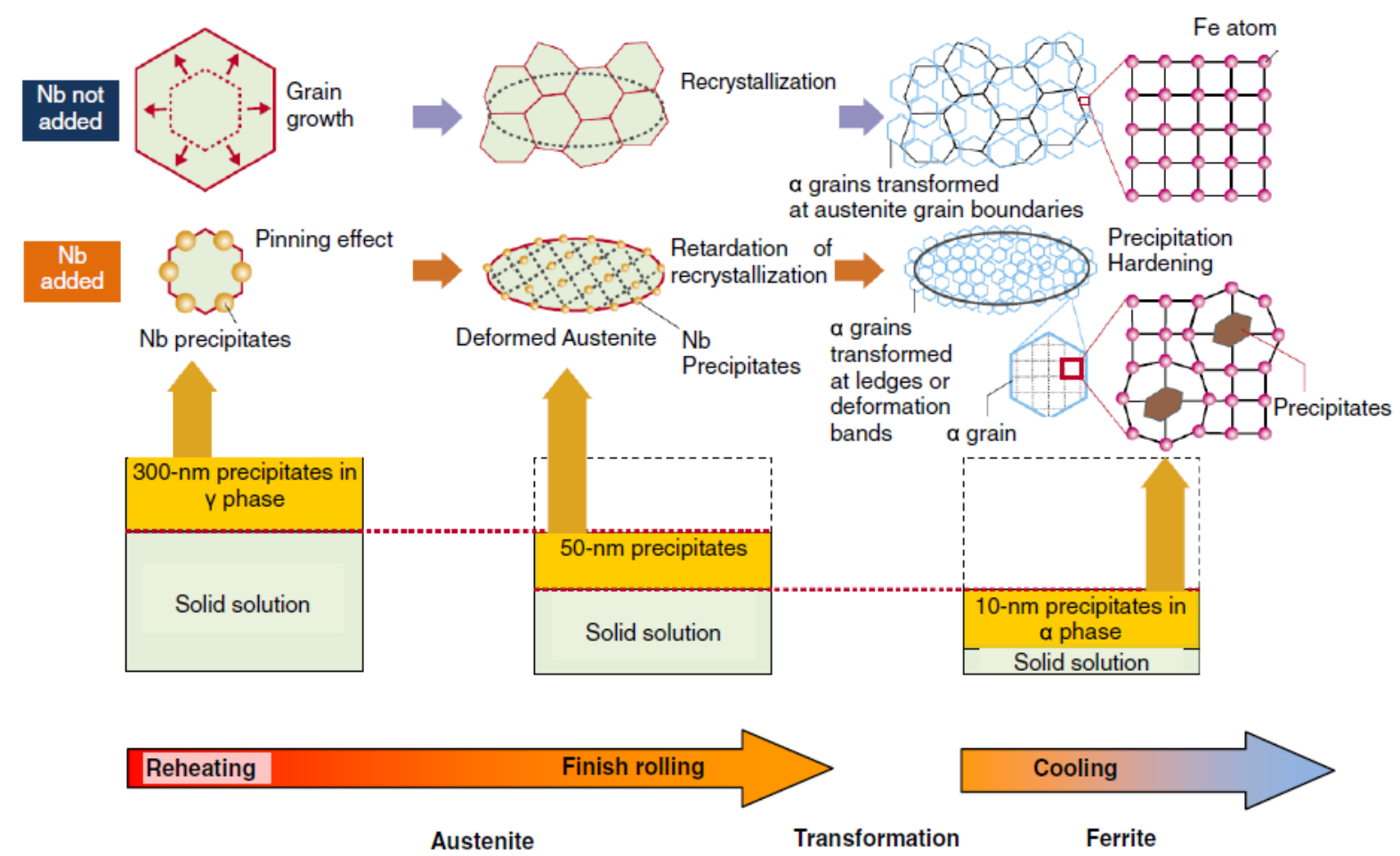

Figura 1. Mecanismos metalúrgicos atuantes durante a laminação controlada de aços microligados ao $\mathrm{Nb}[2]$.

Os mecanismos metalúrgicos mostrados na figura 1 somente são ativados através de uma sequencia perfeitamente sincronizada de temperatura e deformações ao longo do tempo, conforme mostrado na figura 2. A necessidade de se ter tamanho de grão refinado no produto já impõe restrição no crescimento de grão que inevitavelmente ocorre na placa durante seu reaquecimento; portanto, além da eventual limitação nas temperaturas aplicadas nos fornos de reaquecimento, também a presença de $\mathrm{Ti}$ e de $\mathrm{Nb}$ contribui nesse sentido. A fase de esboçamento, onde é aplicada a maior parte da deformação total ao esboço, deve ocorrer sob condições de recristalização plena da austenita entre os passes de laminação, ou seja, sob temperaturas suficientemente altas. Também é altamente recomendável que as deformações aplicadas nos passes sejam crescentes à medida que a temperatura e a espessura do esboço diminuem, pois assim o refino de grão proporcionado pela recristalização é mais intenso e a deformação chega até o núcleo do esboço relativamente mais leve [4]. A laminação deve ser interrompida assim que a austenita não mais se recristalizar completamente no intervalo de tempo entre os passes, pois isso pode dar origem a uma microestrutura com distribuição heterogênea de tamanhos de grão, o que afetará a tenacidade do produto final. Portanto, no final do esboçamento há um período de espera, onde não ocorre laminação, até que o esboço atinja uma temperatura baixa o suficiente para que haja supressão total da recristalização da austenita entre os passes em função 
da precipitação de $\mathrm{NbCN}$ - ou seja, a temperatura de não-recristalização ( $\mathrm{T}_{\mathrm{nr}}$ ). Uma vez atendida essa condição, pode-se iniciar a laminação de acabamento, a qual prossegue até o laminado atingir sua espessura final, dando origem a uma austenita muito encruada. Alguns produtos são resfriados ao ar após a laminação, já obtendo uma microestrutura muito refinada decorrente da intensificação da nucleação da ferrita proporcionada pelo encruamento da austenita que lhe deu origem. Há ainda um ganho de resistência mecânica decorrente da precipitação de $\mathrm{Nb}$ durante $\mathrm{o}$ resfriamento do esboço. O endurecimento por precipitação pode ser intensificado pela adição de $\mathrm{V}$ ao aço presentes em aços que devam apresentar níveis mais elevados de resistência mecânica. Contudo, não se deve esquecer que esse mecanismo de endurecimento compromete parte da tenacidade conseguida pelo refino do tamanho de grão ferrítico [2].

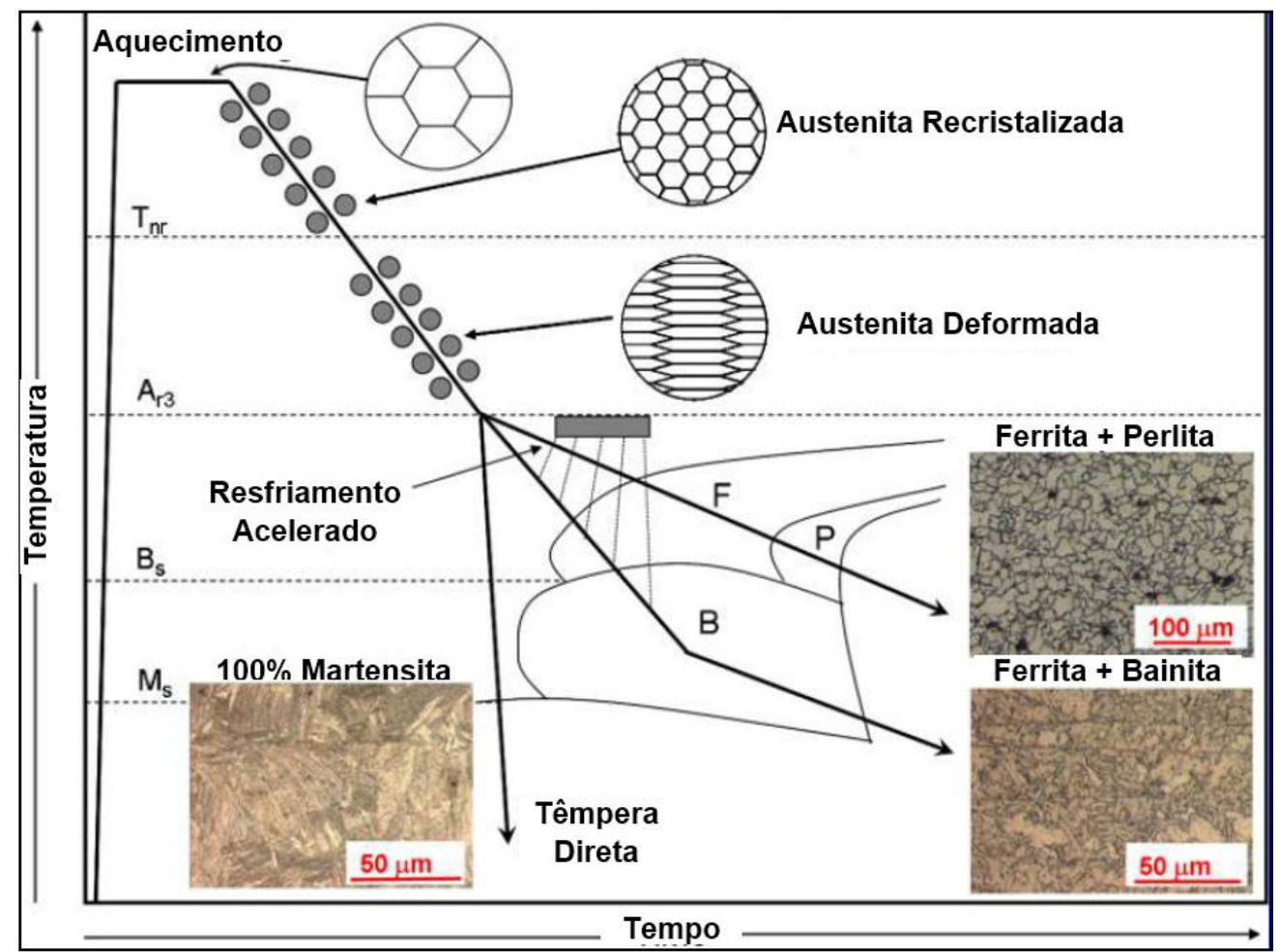

Figura 2. Esquema da evolução da temperatura ao longo do tempo durante a laminação controlada, mostrando as etapas do tratamento termomecânico e sua influência metalúrgica em função da estratégia de resfriamento pós-laminação [3]

Conforme as características específicas do produto desejado, é possível resfriar o esboço de forma acelerada usando água, aumentando ainda mais a taxa de nucleação durante a transformação da austenita para ferrita e conseguindo microestruturas ainda mais refinadas. Dessa forma é possível obter produtos com maior resistência mecânica ou então fabricar o mesmo produto, mas adotando uma composição química mais pobre, especialmente em termos do teor de carbono, com vantagens tanto do ponto de vista do custo como da soldabilidade. Isso fica claro na figura 3, onde se observa que o resfriamento acelerado permite obter o mesmo nível de resistência mecânica, mas usando ligas com menor valor de carbono equivalente [2]. Na verdade, é como que se a água estivesse sendo usada como elemento de liga. Outra possibilidade é a chamada têmpera direta, onde as taxas de resfriamento são tão altas que não ocorre formação de ferrita, mas sim de constituintes mais 
duros, tais como bainita ou até mesmo martensita, permitindo a fabricação de produtos com níveis de resistência mecânica extremamente altos.

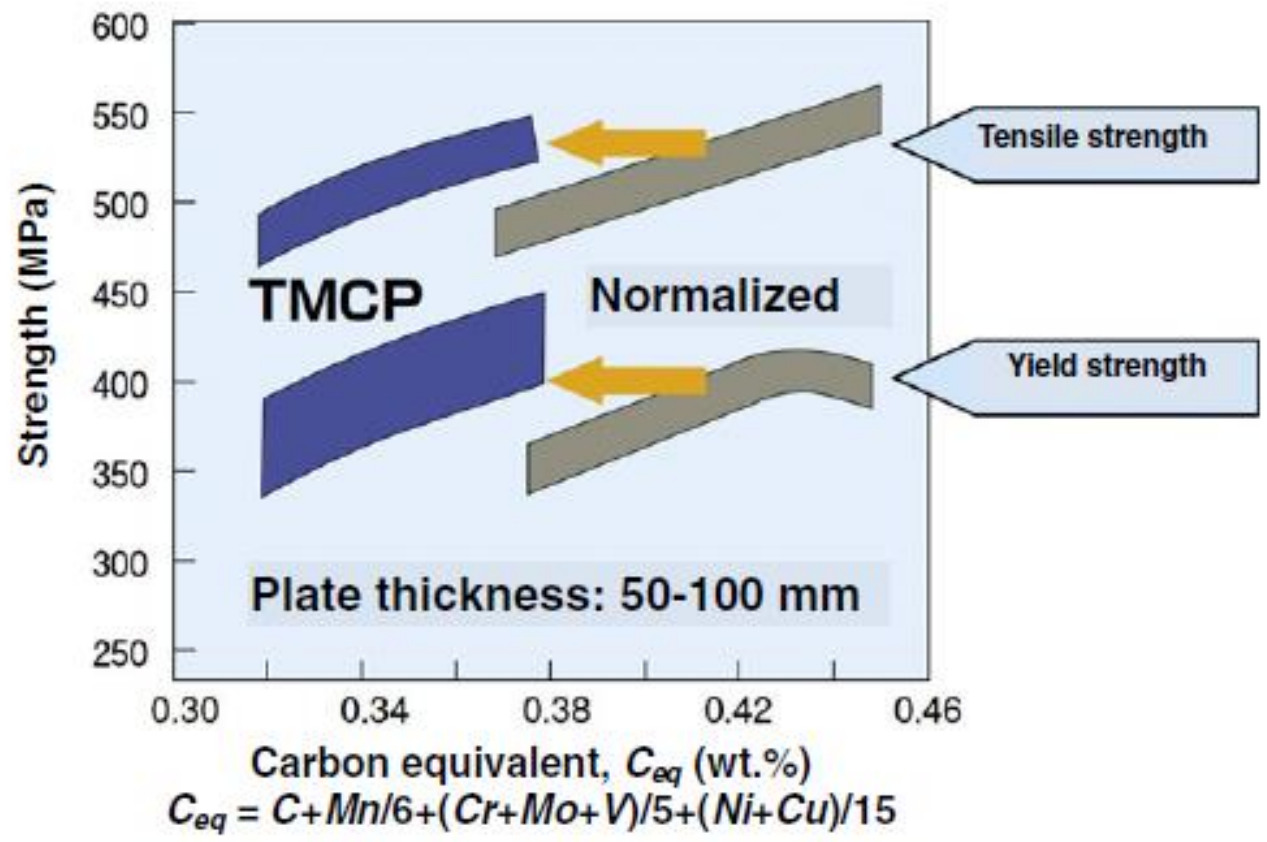

Figura 3. Relação entre carbono equivalente e resistência mecânica para aços processados por tratamento termomecânico e normalizados em forno [2].

Por outro lado, as propriedades mecânicas constituem apenas uma das características a serem satisfeitas por um produto, conforme mostra a figura 4 [5].

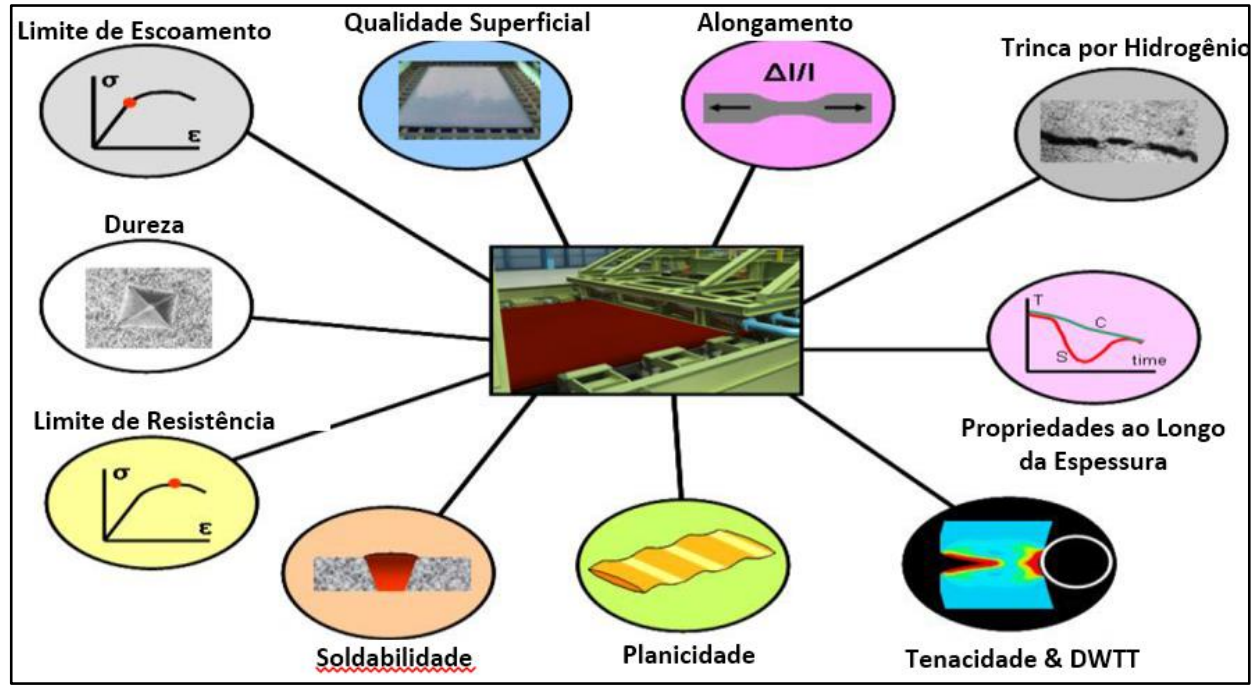

Figura 4. Exemplos dos vários requisitos da qualidade exigidos pelos clientes na chapa grossa acabada [5].

Dentre eles se podem destacar a qualidade superficial, planicidade e ausência de tensões residuais. $O$ atendimento consistente a todos esses requisitos de qualidade, nem sempre compatíveis entre si, requer equipamentos modernos, domínio da tecnologia metalúrgica e automação plena. Os futuros requisitos para os aços processados por tratamento termomecânico estão listados a seguir: maior resistência mecânica para permitir redução do peso nas estruturas; melhor 
tenacidade e resistência para garantir segurança em caso de desastres naturais; maior resistência e confiabilidade contra fadiga e corrosão; melhor soldabilidade para reduzir os custos de fabricação; e melhor trabalhabilidade [2]

\section{MATERIAIS E MÉTODOS}

Foram escolhidos como exemplos neste trabalho aços ARBL bastante representativos da linha de produtos de chapas grossas da Gerdau Ouro Branco: estrutural, graus 80 e $90 \mathrm{ksi}$ (550 e $620 \mathrm{MPa}$, respectivamente). O aço de grau $80 \mathrm{ksi}$ era microligado com baixo $\mathrm{C}$ ao MnNbTiVCrMo na forma de chapas com 25,4 $\mathrm{mm}$ de espessura. Por sua vez, o aço de grau $90 \mathrm{ksi}$ apresenta conformabilidade melhorada, espessura de $15 \mathrm{~mm}$ e é microligado ao MnNbTiV, conforme recomendado em [6]. Em função das características de conformabilidade requeridas, o teor máximo de $\mathrm{S}$ é restrito. As ligas foram processadas na aciaria através de forno panela e desgaseificação $\mathrm{RH}$. Em particular, o aço de grau $80 \mathrm{ksi}$ teve injeção de CaSi.

A prática de tratamento termomecânico seguiu as recomendações descritas em $[4,7]$. As placas foram reaquecidas sob temperatura apenas suficiente para solubilizar o $\mathrm{Nb}$, de acordo com o valor previsto pela equação de Irvine [8], mas com desconto no teor de $\mathrm{N}$ em função de sua reação sob razão estequiométrica com o Ti. Após a fase de espera, o acabamento foi iniciado sob temperaturas inferiores à temperatura de não-recristalização, conforme calculada por Boratto [9], com o final de laminação ocorrendo com o esboço plenamente austenítico, ou seja, sob temperaturas acima de $\mathrm{Ar}_{3}$, conforme calculado por Ouchi [10]. O término da laminação no campo austenítico proporciona uma série de vantagens, como um tratamento termomecânico mais rápido e a supressão da perda de tenacidade em função do encruamento da ferrita. $O$ resfriamento acelerado começou assim que possível, sob temperaturas acima de $\mathrm{B}_{\mathrm{s}}$, conforme calculado por Steven \& Haynes [11]. Dessa forma se evitou a formação excessiva de ferrita poligonal ao ar, o que promove redução na resistência mecânica do esboço. A temperatura final do resfriamento acelerado variou conforme o esboço, desde ligeiramente acima até abaixo de $\mathrm{B}_{\mathrm{f}}$, calculada pelos mesmos autores.

Foi proposto que os esboços deveriam atender às seguintes especificações de propriedades mecânicas: limite de escoamento entre 542 e $662 \mathrm{MPa}$, limite de resistência entre 631 a $741 \mathrm{MPa}$, alongamento total mínimo de $23 \%$ e razão elástica máxima de 0,93, para o aço do grau $80 \mathrm{ksi}$; limite de escoamento entre 600 e 720 MPa; limite de resistência entre 680 a $810 \mathrm{MPa}$ e alongamento total mínimo de 14\%, para o aço do grau $90 \mathrm{ksi}$. Também foram realizados ensaios de dureza para o aço grau 80 ksi e ensaios de dobramento com calço zero para o aço grau 90 ksi. Os resultados de resistência ao impacto Charpy foram determinados sob temperaturas de $-20,-40$ e $-60^{\circ} \mathrm{C}$, mas não foram especificados valores mínimos no âmbito deste trabalho.

\section{RESULTADOS E DISCUSSÃO}

A tabela 1 mostra os resultados obtidos em chapas grossas grau 80 ksi processadas por tratamento termomecânico de aço microligado ao MnNbTiVCrMo. Como se pode observar, os requisitos de propriedades mecânicas foram plenamente atendidos, 
inclusive os resultados dos ensaios de dobramento transversal sob ângulo de $180^{\circ}$, que não estão mostrados nessa tabela. Não foi observada correlação das diversas propriedades mecânicas com os parâmetros de processo aplicados, o que indica relativa estabilidade a variações normais nas condições operacionais.

Tabela 1. Propriedades mecânicas obtidas em chapas grossas de aço microligado ao MnNbTiVCrMo após tratamento termomecânico atendendo ao grau $80 \mathrm{ksi}$.

\begin{tabular}{|c|c|c|c|c|c|c|c|c|}
\hline \multicolumn{4}{|c|}{ Tração (CP Transversal) } & \multicolumn{2}{c|}{$\begin{array}{c}\text { Energia Média Charpy } \\
(\mathrm{CP} \text { Longitudinal, } 1 / 4 \text { Esp.) }\end{array}$} & \multicolumn{2}{c|}{$\begin{array}{c}\text { Dureza Média } \\
1,5 \mathrm{~mm}\end{array}$} \\
\hline $\begin{array}{c}\mathrm{LE} 0,5 \% \\
{[\mathrm{MPa}]}\end{array}$ & $\begin{array}{c}\mathrm{LR} \\
{[\mathrm{MPa}]}\end{array}$ & LE/LR & $\begin{array}{c}\mathrm{A} \\
{[\%]}\end{array}$ & $\begin{array}{c}-20^{\circ} \mathrm{C} \\
{[\mathrm{J}]}\end{array}$ & $\begin{array}{c}-40^{\circ} \mathrm{C} \\
{[\mathrm{J}]}\end{array}$ & $\begin{array}{c}-60^{\circ} \mathrm{C} \\
{[\mathrm{J}]}\end{array}$ & $\begin{array}{c}\text { Face A } \\
{[\mathrm{HV} 10]}\end{array}$ & $\begin{array}{c}\text { Face B } \\
{[\mathrm{HV} 10]}\end{array}$ \\
\hline 591 & 686 & 0,86 & 43 & 430 & 367 & 362 & 223 & 231 \\
\hline 611 & 697 & 0,88 & 44 & 400 & 335 & 358 & 224 & 233 \\
\hline 574 & 677 & 0,85 & 42 & 463 & 448 & 401 & 223 & 229 \\
\hline 597 & 694 & 0,86 & 43 & 437 & 406 & 391 & 223 & 231 \\
\hline 571 & 687 & 0,83 & 44 & 411 & 346 & 338 & 237 & 246 \\
\hline
\end{tabular}

A figura 5 mostra as microestruturas a $1 / 4$ da espessura de chapa grossa grau $80 \mathrm{ksi}$ feita com o aço microligado ao MnNbTiVCrMo, vistas sob diferentes aumentos. As microestruturas apresentaram caráter acicular, muito similar ao que se espera para a bainita de aços com teor muito baixo de carbono submetida ao tratamento termomecânico aqui descrito, além de grãos esparsos de ferrita poligonal ou quasepoligonal. Conforme Meimeth e outros [12], essa microestrutura com predominância de bainita e resíduos de ferrita é típica de aços grau $80 \mathrm{ksi}$, sendo necessária a presença de pelo menos $85 \%$ de bainita na microestrutura para se conseguir esse grau de resistência mecânica. Também é possível observar nessa figura a total ausência de bandeamento microestrutural.

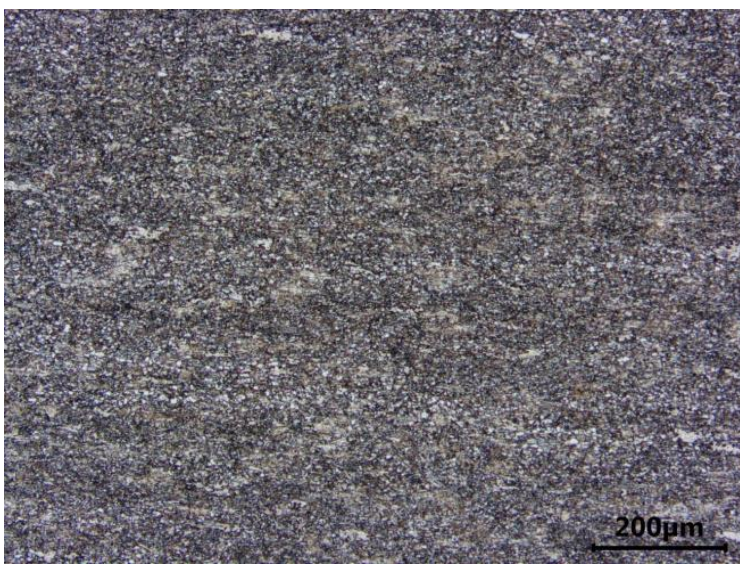

(a) $100 x$

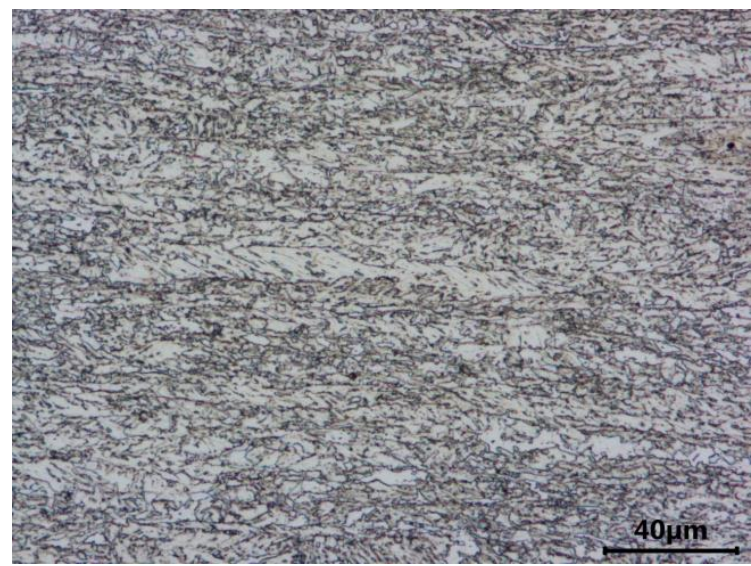

(b) $500 x$

Figura 5. Microestruturas a $1 / 4$ da espessura das chapas grossas grau $80 \mathrm{ksi}$ de aço microligado ao MnNbTiVCrMo. Ataque de nital 3\%.

A tabela 2 mostra exemplos de resultados obtidos em chapas grossas grau $90 \mathrm{ksi}$, com $15 \mathrm{~mm}$ de espessura, processadas pelo tratamento termomecânico de aço microligado ao MnNbTiV. Como se pode observar, os requisitos de propriedades mecânicas foram plenamente atendidos, inclusive os obtidos nos ensaios de dobramento transversal sob ângulo de $180^{\circ}$, que não estão mostrados nessa tabela. Não foi observada correlação das diversas propriedades mecânicas com os 
parâmetros de processo aplicados, o que indica relativa estabilidade a variações normais nas condições operacionais.

A figura 6 mostra as microestruturas a $1 / 4$ da espessura de chapa grossa grau $90 \mathrm{ksi}$ feita com o aço microligado ao MnNbTiV, vistas sob diferentes aumentos. As microestruturas apresentaram caráter acicular, muito similar ao que se espera para a bainita de aços com baixo teor baixo de carbono submetida ao tratamento termomecânico aqui descrito, além de pequena quantidade de ferrita poligonal ou quase poligonal. Também é possível observar nessa figura a total ausência de bandeamento microestrutural.

Tabela 2. Propriedades mecânicas obtidas em chapas grossas com $15 \mathrm{~mm}$ de espessura de aço microligado ao MnNbTiV após tratamento termomecânico, atendendo ao grau $90 \mathrm{ksi}$.

\begin{tabular}{|c|c|c|c|c|c|c|}
\hline \multicolumn{3}{|c|}{ Tração (CP Transversal) } & \multicolumn{3}{c|}{$\begin{array}{c}\text { Energia Média Charpy } \\
\text { (CP Longitudinal, 1/4 Esp.) }\end{array}$} \\
\hline $\begin{array}{c}\mathrm{LE}_{0,2 \%} \\
{[\mathrm{MPa}]}\end{array}$ & $\begin{array}{c}\mathrm{LR} \\
{[\mathrm{MPa}]}\end{array}$ & $\mathrm{LE} / \mathrm{LR}$ & $\begin{array}{c}\mathrm{A} \\
{[\%]}\end{array}$ & $\begin{array}{c}-20^{\circ} \mathrm{C} \\
{[\mathrm{J}]}\end{array}$ & $\begin{array}{c}-40^{\circ} \mathrm{C} \\
{[\mathrm{J}]}\end{array}$ & $\begin{array}{c}-60^{\circ} \mathrm{C} \\
{[\mathrm{J}]}\end{array}$ \\
\hline 621 & 682 & 0,91 & 18 & 458 & 453 & 369 \\
\hline 693 & 744 & 0,93 & 17 & 425 & 358 & 302 \\
\hline 683 & 719 & 0,95 & 16 & 384 & 338 & - \\
\hline 593 & 655 & 0,91 & 19 & 443 & 389 & 416 \\
\hline 668 & 736 & 0,91 & 19 & 425 & 332 & - \\
\hline 645 & 727 & 0,89 & 16 & 359 & 389 & 350 \\
\hline
\end{tabular}

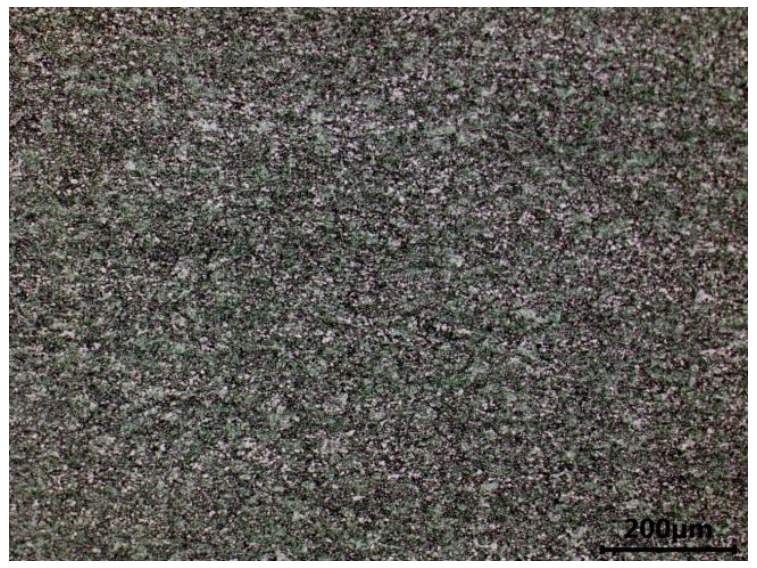

(a) $100 x$

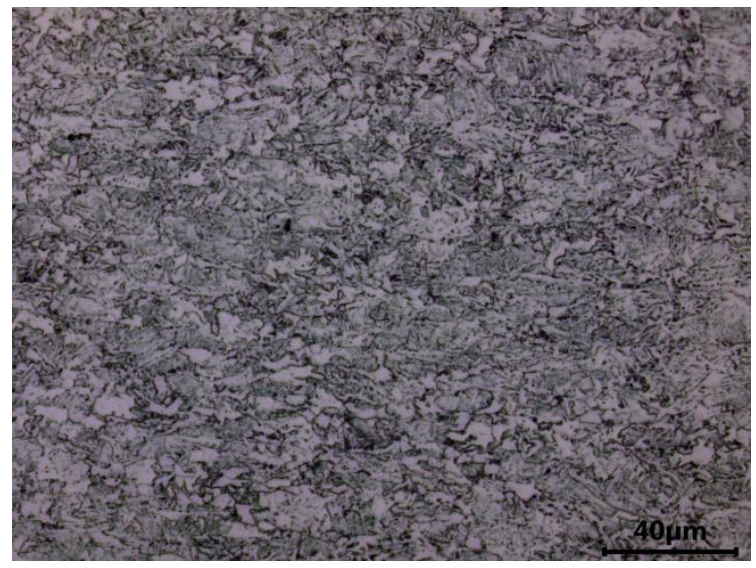

(b) $500 x$

Figura 6. Microestruturas a $1 / 4$ da espessura das chapas grossas grau 90 ksi de aço microligado ao MnNbTiV. Ataque de nital 3\%.

\section{CONCLUSÃO}

O domínio científico e operacional dos tratamentos termomecânicos que podem ser aplicados na laminação de chapas grossas é uma necessidade fundamental para a fabricação econômica de produtos sofisticados. É necessário, mas não suficiente, compreender perfeitamente os mecanismos metalúrgicos envolvidos, deve-se também ter competência na sua transposição às condições industriais, levando-se em conta suas peculiaridades e limitações. Este trabalho mostra um exemplo de como a laminação controlada de aços de alta resistência e baixa liga vem sendo desenvolvida dentro do processo de comissionamento da nova linha de chapas grossas da Gerdau Ouro Branco. 


\section{REFERÊNCIAS}

1 Gorni AA. Os Tratamentos Termomecânicos Garantem a Competitividade dos Produtos Planos de Aço. Industrial Heating - Edição Brasileira, 2012;16:67-71.

2 Nishioka K, Ichikawa K. Progress in Thermomechanical Control of Steel Plates and their Commercialization. Science and Technology of Advanced Materials. 2012;13; 20 p.

3 S. Vervynckt, K. Verbeken, B. Lopez and J. J. Jonas, Modern HSLA steels and role of non-recrystallisation temperature, International Materials Reviews 2012;57(4):187-207.

4 Stalheim, DG. Optimized Production of Niobium Microalloyed Slabs, Plate and Coil. In: $4^{\text {th }}$ International Conference on Thermo-Mechanical Simulation and Processing of Steels - SimPro '16, Ranchi. Proceedings... Steel Authority of India, 2016, 171-184. Brammer M. Future-Proofing the Plate Mill - A Mill Builder's View of Adapting to Changing Customer Needs. In: $2^{\text {nd }}$ Steel Plate Conference Europe. Proceedings... Metal Expert, Düsseldorf, 2016, 23 p.

6 Stalheim DG, Guzela DDN, Gorni AA. Basic Alloy Design Concepts and Steelmaking/ Casting Considerations for Optimized Hot Strip Structural Steel in Yield Strengths from 300 to $700 \mathrm{MPa}$. In: ABM Week. Proceedings... Associação Brasileira de Metalurgia, Materiais e Mineração, Rio de Janeiro, 2016, 11 p.

7 Stalheim DG, Barbosa RANM, Bastos FMMM, Gorni AA, Rebellato, MA. Basic Metallurgy/Processing Design Concepts for Optimized Hot Strip Structural Steel in Yield Strengths from 300 to $700 \mathrm{MPa}$. ABM Week. Processings... Associação Brasileira de Metalurgia, Materiais e Mineração, Rio de Janeiro, 2016, 11 p.

8 Irvine KJ, Pickering FB, Gladman T. Grain-Refined C-Mn Steels. Journal of the Iron and Steel Institute, 1967, 205:161-182.

9 Boratto F, Barbosa R, Yue S, Jonas JJ. The Influence of Chemical Composition on the Recrystallisation Behaviour of Microalloyed Steels. In: Processing, Microstructure and Properties of HSLA Steels. Proceedings... The Metallurgical Society of AIME, Pittsburgh, 1987, p. 51-61.

10 Ouchi C, Sampey T, Kosazu I. The Effect of Hot Rolling Condition and Chemical Composition on the Onset Temperature of Gamma-Alpha Transformation After Hot Rolling. Transactions of the ISIJ. 1982;22(3):214-222.

11 Steven W, Haynes AG The Temperature of Formation of Martensite and Bainite in Low Alloy Steels. Journal of the Iron and Steel Institute. 1956;183:349-359. 